\title{
Investigation of mean monthly maximum temperature of Thailand using mapping analysis method: A case study of summer 1987 to 2019
}

\author{
Nutthakarn Phumkokrux ${ }^{1, *}$, and Somkamon Rukveratham ${ }^{1}$ \\ ${ }^{1}$ Department of Geography, Faculty of Education, Ramkhamheang University, Bangkok, Thailand
}

\begin{abstract}
This study aims to study distribution of air temperature characteristics and to analyse the trend of mean monthly maximum temperature changed in summer of Thailand from 1987 to 2019. The study was performed by gathering the temperature data from 83 meteorological stations around Thailand. The study focused on the months February to May in the years 1987 to 2019. Then, distribution of air temperature characteristics maps and graph of each month in each year are created to analyse the distribution and trend of mean monthly maximum temperature over the past 33 years. The results showed that, for every year, the mean monthly maximum temperature increased from February to April and decreased in May. Moreover, the maps presented that the air temperature in the western of Thailand was higher than the eastern of Thailand. Furthermore, the temperature trend illustrated that the mean monthly maximum temperature of all months in summer was increasing, especially May. Totally, the trend of the air temperature in summer was rising by $0.0087^{\circ} \mathrm{C}$ per year.
\end{abstract}

\section{Introduction}

Global warming and climate change become major dangerous signals which all sectors around the world interested. These signals cause many problems to natural ecosystem and biodiversity. Moreover, high air temperature can affect to public health such as heat stroke, skin cancer, food poisoning, etc. However, Thailand is located in Southeast Asia which is near the equator at $5^{\circ}$ $37^{\prime \prime} \mathrm{N}-20^{\circ} 28^{\prime \prime} \mathrm{N}$ and $97^{\circ} 21^{\prime \prime} \mathrm{E}-105^{\circ} 37^{\prime \prime}$ [1]. This location cause Thailand to get extreme influence of solar radiation then air temperature in Thailand is hot all year especially in summer season. From surveillance of the Department of Disease Control, the deceases from high air temperature in summer from 2015-2018 are 56, 60, 24 and 18 people, respectively. Moreover, the data from Strategy and Planning Division presented that the patient from global warming in summer of Thailand (2014-2017) are $3,054,3,523,4,002$, and 3,409, respectively [2]. Furthermore, abnormal air temperature lead Thailand to be top 10 of countries that have high risk of climate change between 1997-2016. [3] this situation can affect to natural ecosystem and biodiversity in Thailand such as drought, flooding, bleached coral, coastal erosion, agricultural effects and economic impact. [4,5]

From all problems mentioned above, the authors are interested in how air temperature in Thailand changed. Therefore, this works aims to answer that how the distribution of air temperature characteristics be in summer season, how air temperature changed over 33 years past and how the trend of mean monthly maximum temperature changed from now to future. Moreover, this study could be an evidence which warns all sectors in Thailand to be aware about the air temperature changed and global warming in Thailand.

\section{Methodology}

\subsection{Study area, Data and Definitions}

The study areas using in this study included 6 regions around Thailand. The regions are separated by Meteorological Department of Thailand which are; Northern, Northeastern, Central, Eastern, Southern East coast and Southern West coast of Thailand [6]. The study areas are shown in figure 1.

This study collected the mean monthly maximum temperature data in the period of summer from 1987 to 2019 (33 years), which recorded by Meteorological Department of Thailand from 83 meteorological stations around Thailand. The details of meteorological stations are presented in table 1.

For the word definitions, there are 2 words which often used in this study. 1) Mean monthly maximum temperature means the average of maximum temperature which recorded in over the month at meteorological station. And 2) Summer period defined by Meteorological Department of Thailand means the period of February to May in each year.

\footnotetext{
Corresponding author: ph.nutthakarn@hotmail.com
} 


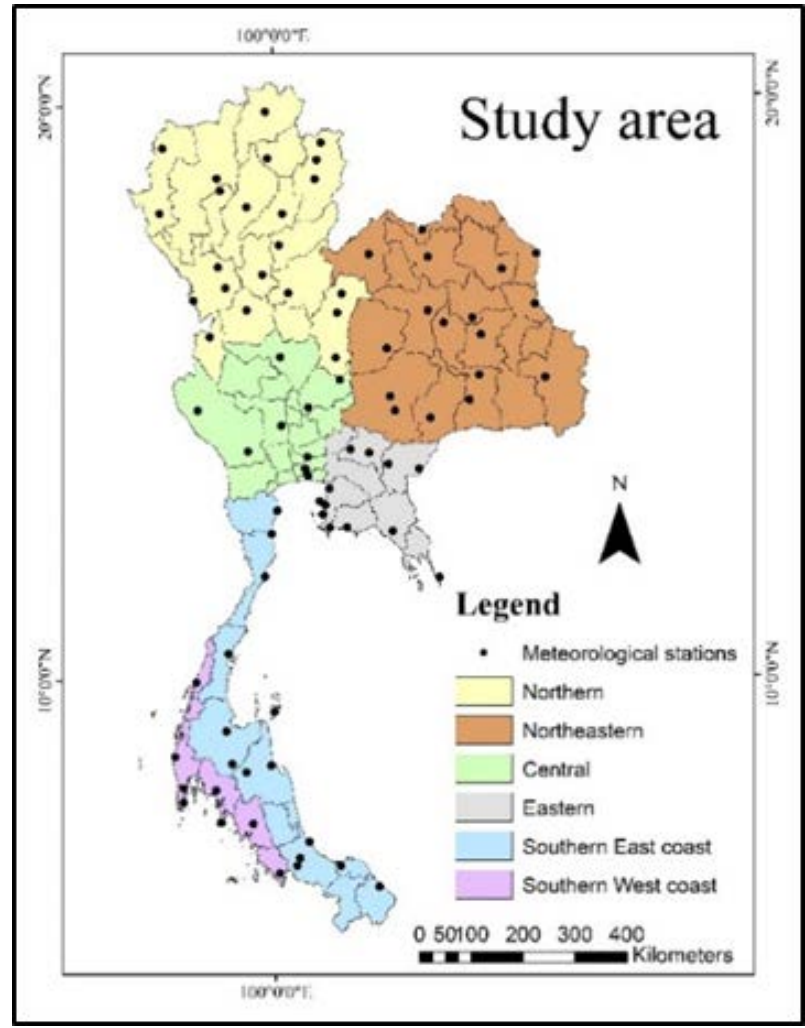

Fig. 1. Study areas in this work

\subsection{Procedures}

\subsubsection{Preparation of concerned data.}

All concerned data are prepared which are Mean monthly maximum temperature of summer season from 1987 to 2019 of 83 Meteorological stations all Thailand and geographic coordinate of 83 Meteorological stations data.

\subsubsection{Maps creation.}

Mean monthly maximum temperature maps of all months in each year are created. The classification of air temperature characteristics followed the criteria presented in table 2 .

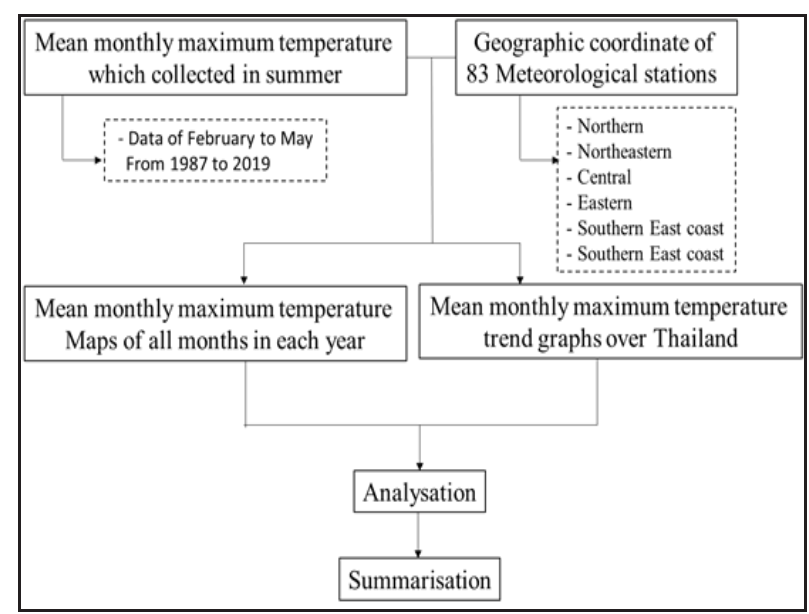

Fig. 2. Conceptual framework [7]

Table 1. The detail of meteorological stations in each region [4]

\begin{tabular}{|c|c|c|}
\hline Regions & $\begin{array}{l}\text { number of } \\
\text { provinces }\end{array}$ & $\begin{array}{c}\text { number of } \\
\text { meteorolog } \\
\text { ical } \\
\text { stations }\end{array}$ \\
\hline Northern & 15 & 22 \\
\hline Northeastern & 20 & 17 \\
\hline Central & 18 & 10 \\
\hline Eastern & 8 & 12 \\
\hline Southern & & \\
\hline Southern East coast & 10 & 14 \\
\hline Southern West coast & 6 & 8 \\
\hline Total & 77 & 83 \\
\hline
\end{tabular}

Table 2. Air temperature characteristics [4]

\begin{tabular}{|l|c|c|}
\hline $\begin{array}{c}\text { Air temperature } \\
\text { characteristics }\end{array}$ & $\begin{array}{c}\text { Temperature } \\
\text { range }\left({ }^{\circ} \mathbf{C}\right)\end{array}$ & $\begin{array}{c}\text { Color } \\
\text { shown in } \\
\text { map }\end{array}$ \\
\hline Very Cold & $\leq 7.9$ & \\
Cold & $8.0-15.9$ & \\
Cool & $16.0-22.9$ & \\
Normal & $23.0-34.9$ & \\
Hot & $35.0-39.9$ & \\
Very hot & $\geq 40$ & \\
\hline
\end{tabular}

\subsubsection{Data analyzing.}

This part can be separated into 2 part. 1) Distribution of air temperature characteristics of every months in summer from 1987 to 2019 which illustrated in the maps are analysed. 2) Analysis of the trend of mean monthly maximum temperature of Thailand are prepared to illustrate how the temperature changed over 33 years past. Then, Summarization are prepared. All methods are presented in figure 2 .

\section{Results}

\subsection{Distribution of air temperature characteristics of every months in summer over 1987 to 2019}

Summer season in Thailand starts from February to May in all year. In this period, the influence of northeast monsoon is weak and starts to change to southwest monsoon period. According to figure 3 figure 4 figure 5, the air temperature characteristics of mean monthly maximum of Thailand started to increase from February to April. The air temperature was at peak in April. Then, the air temperature slightly drops in May. Moreover, the maps presented that the air temperature was rising and expand from the west to east of the upper of Thailand (Northern, Northeastern and Central of Thailand)

In February of the most years were in normal range except 1994, 1998 and 2005. There were in hot range around the upper of Thailand. Then, the air temperature was higher in March especially the upper of Thailand which were in hot range except 2001. However, the air 


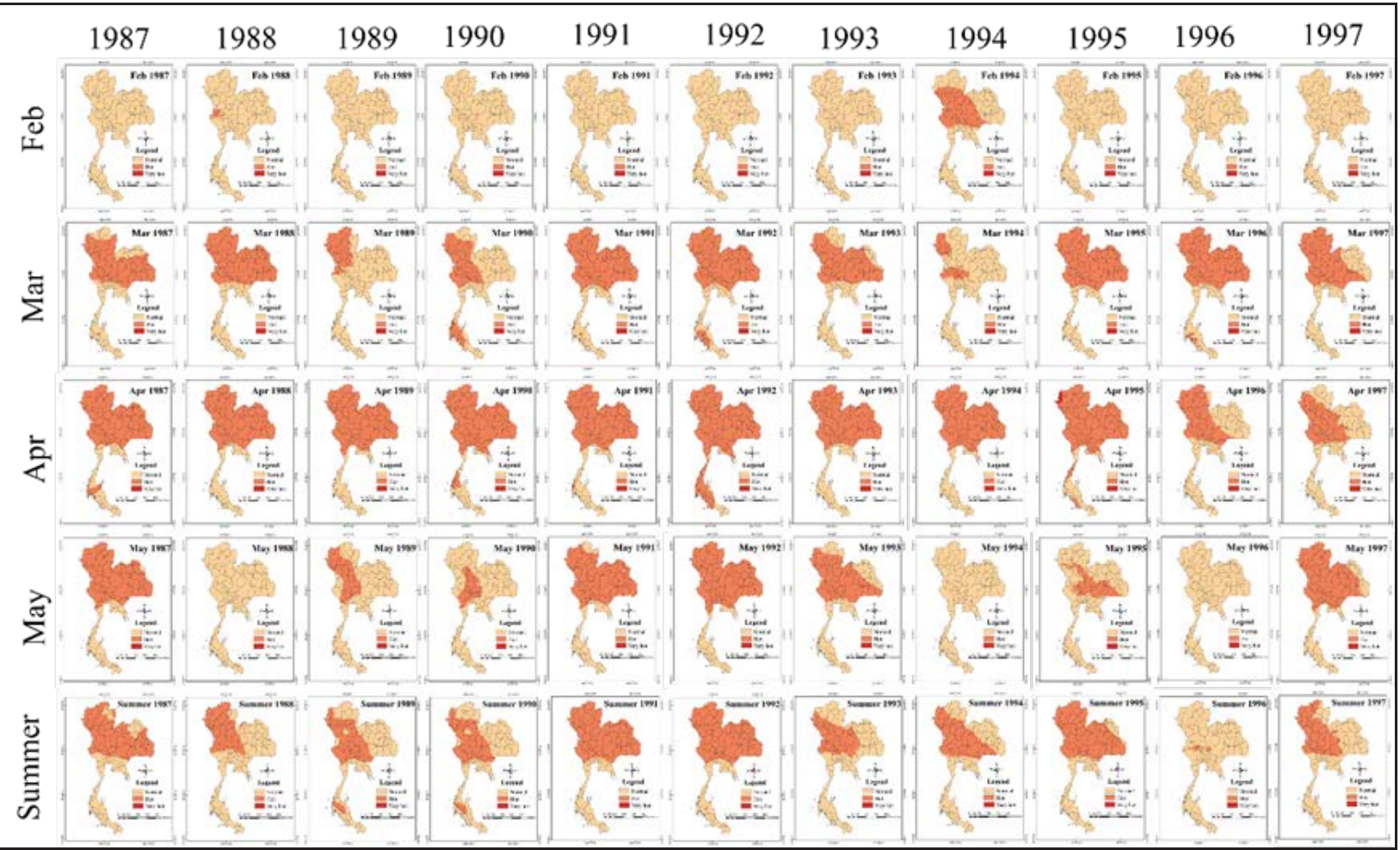

Fig. 3. Distribution of air temperature characteristics of Summer in 1987 to 1997

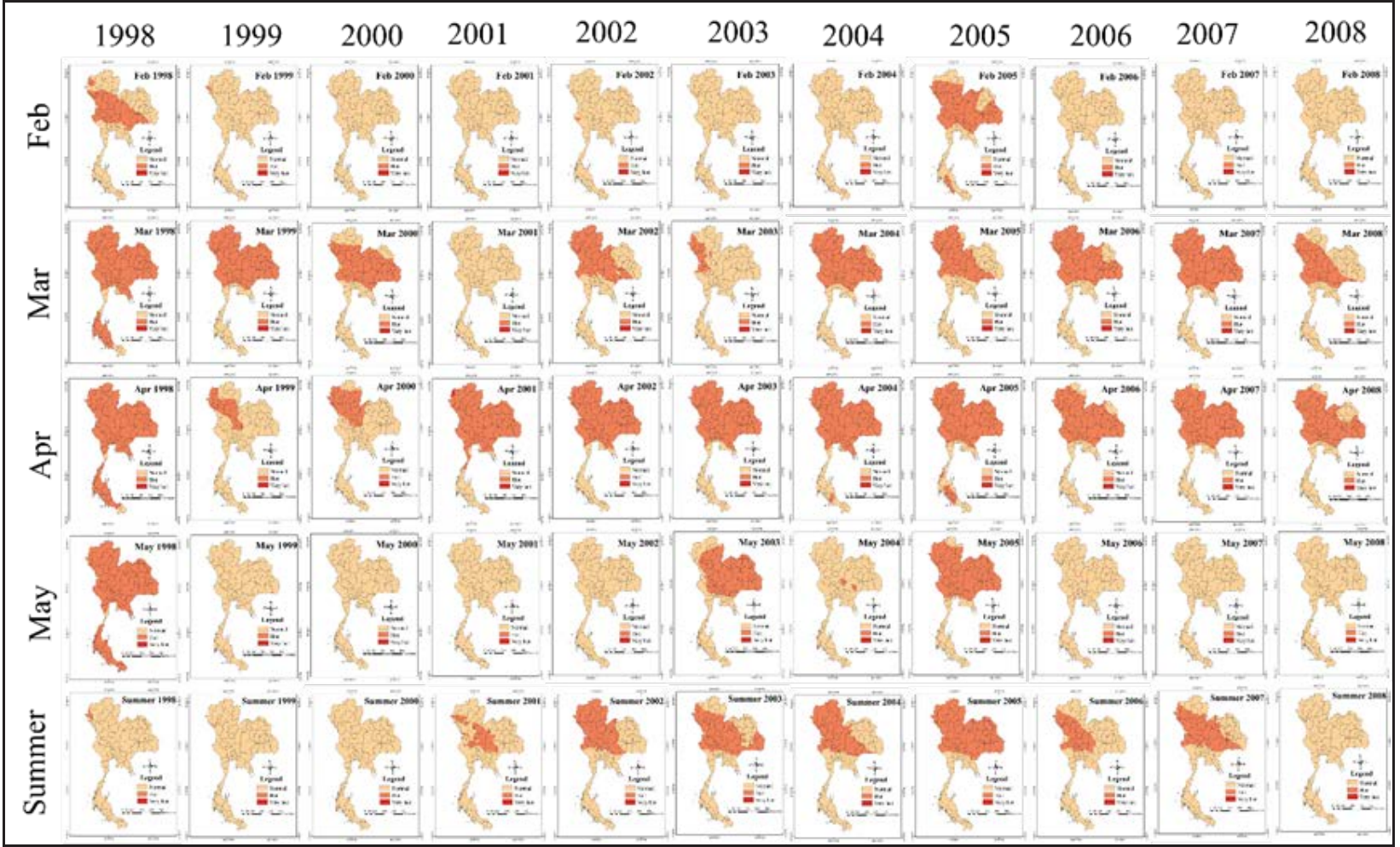

Fig. 4. Distribution of air temperature characteristics of Summer in 1998 to 2008

temperature characteristics were mostly in normal range for southern of Thailand. Then, the mean monthly maximum of April in all years were rising to be the hottest in summer. The upper of Thailand was mostly in hot range every year and the air temperature of the southern Thailand of 1987, 1992, 1995, 1998, 2010, 2013,
2016 and 2019 were also in hot range. Moreover, the maps of 2010, 2016 and 2019 of April illustrated that the most area of Thailand were in hot range and some of northern (in 2010, 2016 and 2019) and central area of Thailand (in 2016) were in very hot range. In May, the air temperature characteristics of mean monthly maximum of 


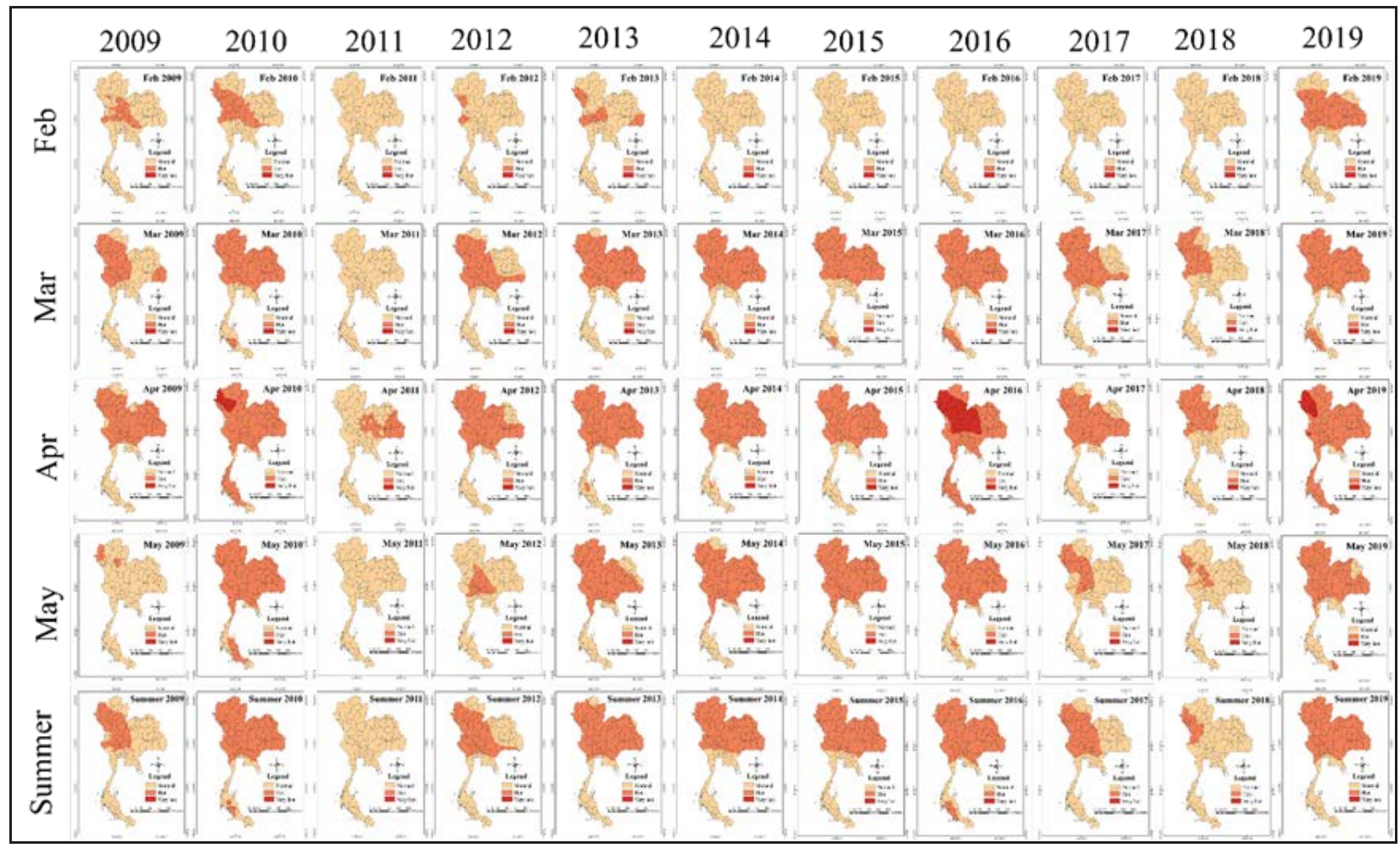

Fig. 5. Distribution of air temperature characteristics of Summer in 2009 to 2019

Thailand were decreasing in all years, however; the air temperature of the most areas of upper of Thailand were still mostly in hot range except 1988, 1994, 1996, 1999, 2000, 2001, 2002, 2004, 2006, 2007, 2008 and 2011 which the most areas were in normal range. For the total of Summer, the maps illustrated that the most areas of the upper of Thailand were still in hot range, however, the southern of Thailand were still in normal range in every year.

\subsection{Analysing of the trend of mean monthly maximum temperature of Thailand over 1987 to 2019}

From the Figure 6 to 10, the mean monthly maximum temperature of Thailand in February to May was analysed. The data from 1987 to 2019 were illustrated in the line graphs. The trendline of each month was constructed as linear line. The trendline was fit by the method of least squares (done by MS excel). The slope of trendline indicated the temperature change per year. The results showed that the trends of temperature in all four months were increased. In general, the hottest month among the four was April and the coolest month was February. However, the month with highest temperature rise was May. The trend of maximum temperature of May was increased by 0.0221 degree Celsius per year. In general, the rainy season will appear around the middle of May which decreased temperature. However, this month had the highest temperature rise because the influence of abnormal rain and drought were become stronger. Thus, the temperature in May would still rise higher. On the other hand, April, which is the hottest month, had the lowest temperature rise. Due to the angle of the sun and little precipitation, this month has normally high temperature. Therefore, this month might receive the lower effect from temperature rise. By the average of the four months, the temperature was increased by 0.0087 degree Celsius per year.

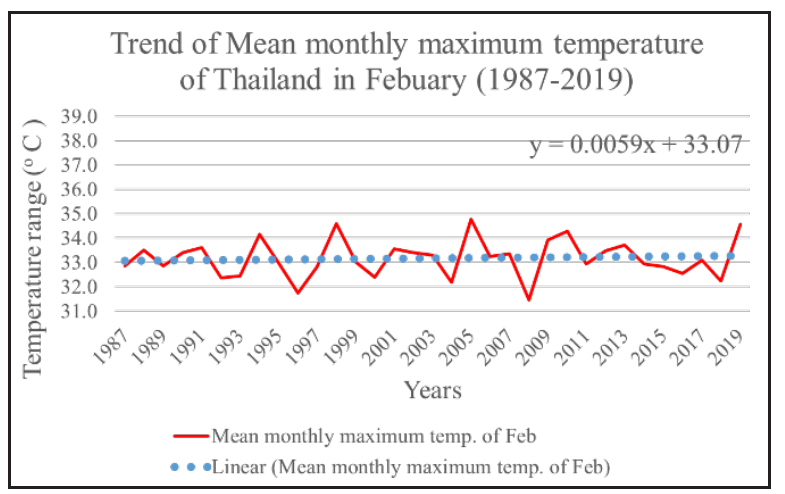

Fig. 6. Trend of Mean monthly maximum temperature of Thailand in February (1987-2019)

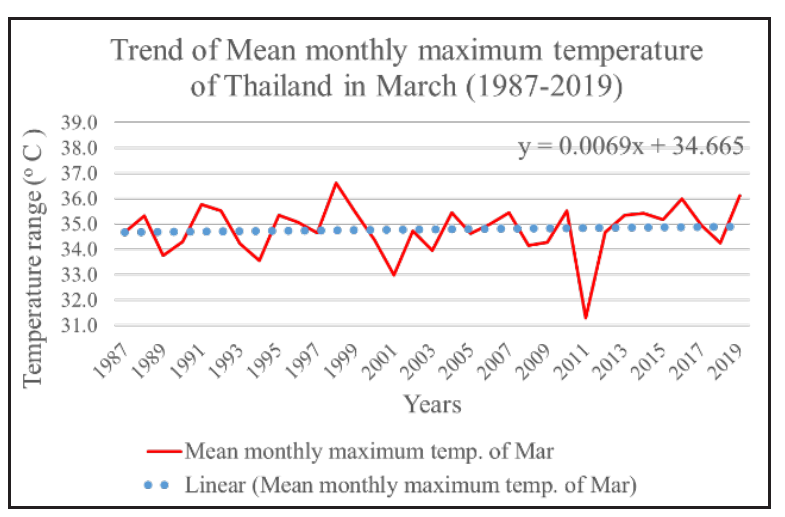


Fig. 7. Trend of Mean monthly maximum temperature of Thailand in March (1987-2019)

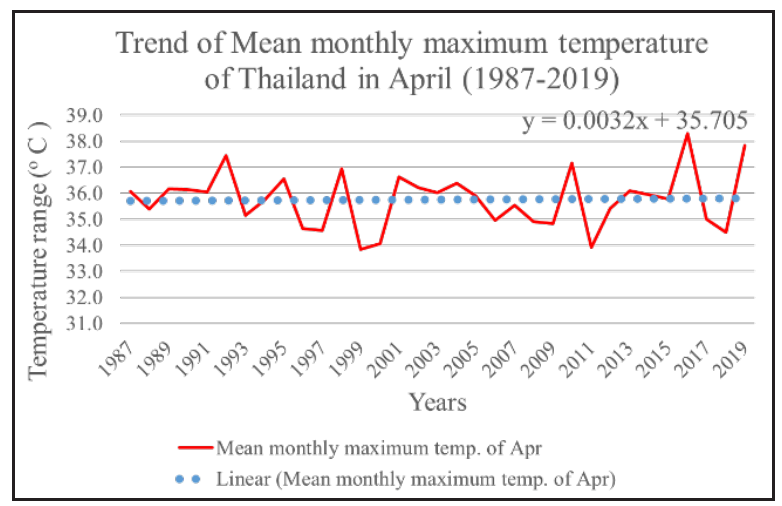

Fig. 8. Trend of Mean monthly maximum temperature of Thailand in April (1987-2019)

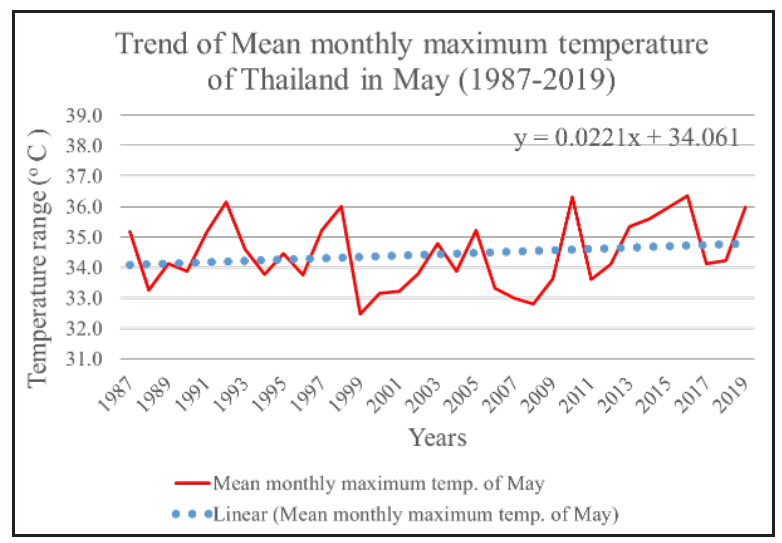

Fig. 9. Trend of Mean monthly maximum temperature of Thailand in May (1987-2019)

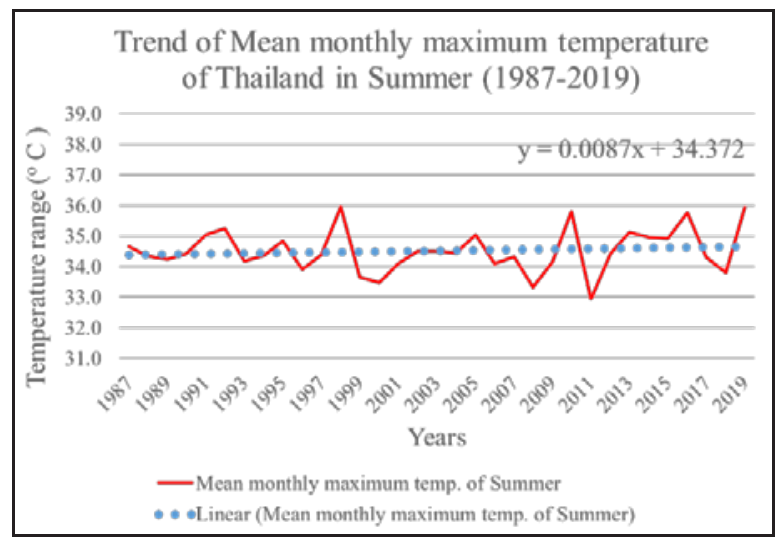

Fig. 10. Trend of Mean monthly maximum temperature of Thailand in Summer (February to May of 1987-2019)

\section{Conclusions and suggestions}

Abnormal air temperature becomes an important problem which all parties interested included Thailand. The presented maps showed that the mean monthly maximum temperature started to rise from the beginning of summer and hit the peak in April. Moreover, some of areas in upper of Thailand face with the air temperature characteristic in hot and very hot range. Then, the air temperature become decrease in May. Furthermore,
Thailand was affected by El Nino in summer of 1987, 1992, 1998, 2010, 2016 and 2019 which caused Thailand to have high temperature than normal. However, La Nina affected to Thailand and caused Thailand to have low temperature than normal in summer of 1989, 1999, 2000, 2001, 2008, 2009, 2011, 2012 and 2018. [8] Totally, the trendline graph of the air temperature of summer (February to May) was raised around 0.0087 degree Celsius per year. Therefore, it might designate that Thailand is facing to the abnormal temperature. For the drawback of this study is that the authors focus on just mean monthly maximum temperature of summer. This might be not enough to indicate that how strong of influence of global warming affecting on Thailand. Therefore, next study should focus on other factors such as relative humidity, rainy record, winds.

Authors would like to acknowledge to Meteorological Department of Thailand for supporting the data of mean monthly maximum temperature, geographic coordinate of 83 meteorological stations around Thailand data and all concerned data which are necessary in this study.

\section{References}

1. Worldatlas. [Internet]. Where is Thailand?; 2015 [cited 2019 Jun 5] Available from: https:/www.worldatlas.com/as/th/where-isthailand.html

2. Department of Disease. [Internet]. Prediction of Disease and Health Hazard; 2019 [updated 2019 Apr 14; cited 2019 May 31] Available from: https://ddc.moph.go.th/th/site/office_newsview /view/5360

3. D. Eckstein, M.L. Hutfils and M. Winges [Internet]. Global Climate Risk Index 2019. Bonn: Germanwatch; 2019 [cited 2019 Jun 5] Available from: https://germanwatch.org/en/16046

4. Miko U.F.Kirschbaum. The temperature dependence of soil organic matter decomposition, and the effect of global warming on soil organic $\mathrm{C}$ storage. Soil Biology and Biochemistry 1995; 27(6): 753-760.

5. J. Joireman, H. . Trueloveb and B. Duellc. Effect of outdoor temperature, heat primes and anchoring on belief in global warming. Journal of Environmental Psychology 2010; 30(4): 358-367.

6. Meteorological Department of Thailand. [Internet]. Climate of Thailand; 2019 [cited 2019 Apr 1] Available from: https://www.tmd.go.th/info/info.php?FileID

7. N. Phumkokrux. A Study of Average Monthly Maximum Temperature change in Thailand from 2007-2016. Proceeding of SMARTS7 2016; 7: 411421

8. Bureau of Meteorology Australian Government. [Internet]. Enso Outlook History; 2019 [cited 2019 Jul 1] Available from: http://www.bom.gov.au/climate/enso/outlook/\#tabs= ENSO-Outlook-history 